\title{
THE INFLUENCE OF THE SOCIAL ENVIRONMENT ON SEXUAL MATURATION IN MALE MICE
}

\author{
J. G. VANDENBERGH \\ Division of Research, North Carolina Department of Mental Health, \\ Raleigh, North Carolina, U.S.A.
}

(Received 2nd May 1970, revised 20th fuly 1970)

\begin{abstract}
Summary. Albino male mice were reared from weaning in the presence of an adult female, in the presence of an adult male, or in the absence of an adult. At 36, 48, 60 and 78 days of age, males in samples from each rearing condition were killed to assess their reproductive state. The testicular development of young males was most rapid when they were reared in the presence of an adult female. By 78 days of age, this advantage was lost when the males were compared to those reared without an adult present. In contrast to the effect of an adult female, the presence of an adult male had an inhibitory effect on testicular and accessory gland development. The inhibition was most pronounced at 78 days of age.

The inhibition of sexual maturation found in this experiment contrasts with an earlier finding that the presence of males accelerates female development. This dual rôle of the male may be an important factor in the dynamics of rodent populations by increasing the availability of mature females and reducing the reproductive capabilities of potential competitors for these females.
\end{abstract}

\section{INTRODUCTION}

The purpose of the present study was to determine whether the presence of either an adult male or an adult female could modify the rate of sexual maturation in male mice. The possibility that male sexual maturation may be influenced by the presence of an adult stems directly from the discovery that female mice reared in the presence of an adult male attain first oestrus 20 days earlier than females reared in the absence of an adult male (Vandenbergh, 1967). Further experiments showed that the physical presence of an adult male was not necessary; male odour alone accelerated female sexual maturation (Vandenbergh, 1969).

The finding that the sexual development of females can be strongly accelerated by a male pheromone extends numerous earlier studies on mice showing that exteroceptive stimuli associated with a male strongly influence adult female reproductive performance. Such studies on the rôle of male stimuli were reviewed by Parkes \& Bruce (1961) and Whitten (1966). The 
findings most pertinent to the present study were those that showed that the presence of adult male mice or their odours can stimulate a synchronous wave of oestrus in groups of adult females (Marsden \& Bronson, 1964; Whitten, Bronson \& Greenstein, 1968).

The possibility that the reproductive state of males can be modified by social stimulation has received only limited attention. Steinach (1936) found reproductive atrophy in unmated male rats denied access to females or female odours and suggested that female odour may be a requisite stimulus for maintenance of the reproductive system. More recently, Drori \& Folman (1964) were able to show that atrophy of the reproductive system occurred in unmated male rats whether or not they were exposed to female odours. It was further shown that reproductive atrophy occurred in all-male groups even when presented with graded intensities of female odours (Folman \& Drori, 1966). The maintenance of the reproductive organs in male rats thus appears to be due to heterosexual mating rather than odour.

In a recent study, Fox (1968) explored the possibility that the presence of an adult female may have an effect on the rate of sexual maturation in male mice. In two separate experiments, mice were reared either to 37 or to 56 days of age in isolation, in groups of four, or in groups of four with an adult female. They were then killed and their reproductive state was assessed. The measures taken at 37 days of age apparently indicate that the presence of an adult female slightly accelerated the sexual development of young males. This stimulatory effect of the female on the male reproductive tract did not persist until 56 days of age; in fact, the results indicated that an inhibition had occurred. The results of this study must be interpreted with some caution because no attempt was made to standardize litter size before weaning and because the treatment groups were apparently not reared in separate rooms.

The studies of social factors influencing male sexual capabilities have focussed on the presence of an adult female as a stimulus and have ignored the possibility that an adult male may also have a stimulatory or inhibitory effect on reproductive development. In the present study, an attempt will be made to assess the rôle of both sexes in influencing male sexual development and adult reproductive status by rearing groups of males in the presence of an adult male, with an adult female, or in the absence of an adult of either sex.

\section{METHODS}

One hundred and twenty closed colony, albino male mice (Mus musculus) were used in this experiment. The animals were derived from litters that had been reduced to six young on the day following birth to reduce variability in neonatal nutrition or other factors due to litter size. At 21 days of age, the male mice were weaned, toe-clipped for identification and placed into groups of five by the split-litter technique to avoid having siblings present in the same group. The mice were housed in $40 \times 30 \times 20 \mathrm{~cm}$ stainless steel cages on San-i-cel bedding. Unrestricted access to Purina Laboratory Chow and tap water was provided.

The resultant twenty-four groups of mice were randomly assigned to three treatment categories: (a) an adult male was placed in each of eight cages, 
(b) an adult female in each of eight cages, and (c) the remaining eight cages were left without an adult. All adults used as stimulus animals were between 80 and 100 days of age and were of proven fertility and each was assumed to be of equal effectiveness as a stimulus animal. The groups containing an adult male or no adult were kept in a room which did not contain any adult females and, similarly, the groups containing an adult female were kept in a room which did not contain any adult males. The temperature in both rooms was maintained at $75 \pm 3^{\circ} \mathrm{F}$ and each was lighted for $12 \mathrm{hr}$ per day by overhead fluorescent lamps.

Mice in two groups from each treatment category were killed at 36, 48, 60 and 78 days of age by an overdose of ether. After weighing the bodies to the nearest $0.1 \mathrm{~g}$, the left testis, left epididymis and seminal vesicles were removed and immediately fixed. The seminal vesicles were fixed in alcohol for $30 \mathrm{~min}$ and then dissected free of extraneous tissue and weighed to the nearest $0 \cdot 1 \mathrm{mg}$. The testis and epididymis were fixed in Bouin's solution for $24 \mathrm{hr}$ before being trimmed and weighed. The precautionary steps taken before weighing the organs are essential to reduce errors in weight due to rupture and loss of fluid from the organs, especially the seminal vesicles.

Following fixation, testes were sectioned at $7 \mu$ using standard paraffin-wax techniques. The diameter of four seminiferous tubules from each testis was measured with an ocular micrometer and the mean of these four measures was used to calculate the treatment mean at each of the four ages used. Tubules chosen for measurement were those with a circular configuration found in the central portion of the testis.

During the course of the experiment, three mice died or escaped from their cages, one in each of the treatment categories. Gonsequently, nine mice were randomly eliminated from the data analysis to equalize the number in each cohort under each treatment.

\section{RESULTS}

The onset of first oestrus as assessed by the appearance of vaginal cornification represents an accurate and convenient measure of the attainment of sexual maturity in female mice but no measure of equivalent value is available to judge the reproductive state of males. As a consequence, a number of indices of reproductive development were utilized in this experiment: testis weight, seminiferous tubule diameter, seminal vesicle weight and epididymal weight.

The means of each of the four measurements of reproductive maturity at 36,48 , 60 and 78 days of age are shown in Text-fig. 1. Inspection of the data failed to reveal significant differences between cage means and as a result each point represents the mean value for nine animals. An analysis of variance was calculated for each measure and treatment sums of squares were partitioned completely into single-degree-of-freedom comparisons by the technique described by Steel \& Torrie (1960). F-tests were calculated at the 0.05 level of significance (Table 1). For each measure, significant interaction was present between age and social environment indicating that the means presented in Text-fig. 1 are of primary interest. Main effect means are accordingly of less interest, despite the fact that main effects were significant in many cases (Table 1). 
The testicular weight of males exposed to an adult female was significantly greater than that of males exposed to an adult male at 36, 48 and 78 days of age (Text-fig. 1, upper left). The testes of males reared in the absence of an adult were intermediate in weight except at 60 days of age when they fell to levels significantly below those of males exposed to an adult female. Spermatozoa
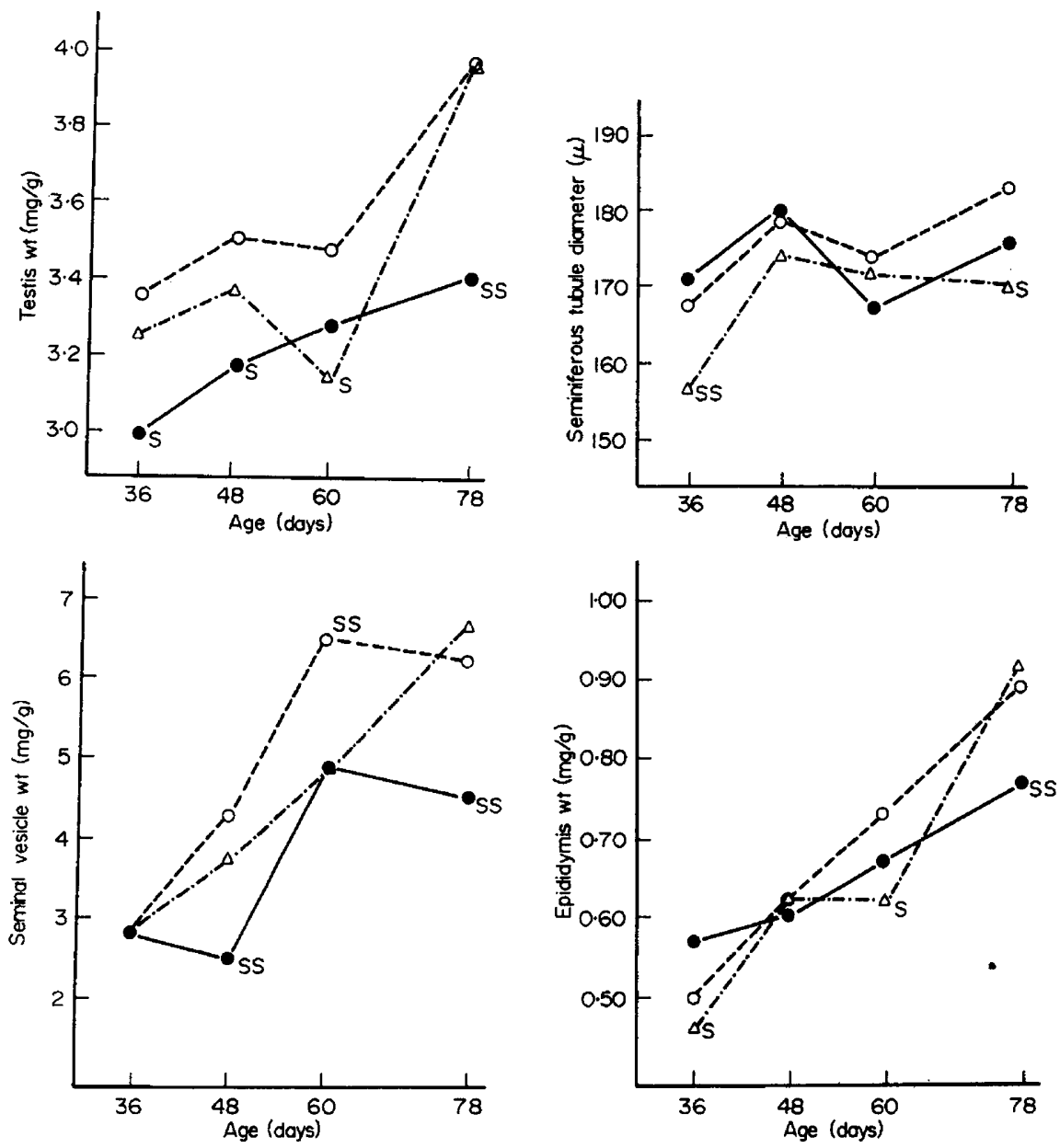

TEXT-FIG. 1. The mean weights of the testes, seminal vesicles and epididymis in $\mathrm{mg} / \mathrm{g}$ of body weight and mean seminiferous tubule diameter in microns at $36,48,60$ and 78 days of age of male mice reared under three social conditions $(O$, female present; $\bullet$, male present; $\Delta$, no adult). Significant differences $(P<0.05)$ between the means at each age are indicated by ' $S$ ' if the most distant mean is reliably different or by 'SS' if both means are reliably different.

were present in the testes of all the males at each age and the only significant differences in the diameter of the seminiferous tubules occurred at 36 and 78 days (Text-fig. 1, upper right). Males denied the presence of an adult had smaller seminiferous tubules than either of the other treatment groups initially and their tubules were also smaller at 78 days than those of males exposed to an adult female. 
TABLE 1

THE RESULTS OF THE ANALYSIS OF VARIANGE OF THE MEASURES OF PHYSICAL AND SEXUAL MATURATION AT FOUR TIME INTERVALS UNDER THREE SOCIAL CONDITIONS

\begin{tabular}{|c|c|c|c|c|c|c|}
\hline \multirow[b]{2}{*}{ Source } & \multirow[b]{2}{*}{ d.f. } & \multicolumn{5}{|c|}{ Mean squares } \\
\hline & & $\begin{array}{c}\text { Body } \\
w t(g)\end{array}$ & $\begin{array}{c}\text { Testis } \\
\text { wt }(m g / g)\end{array}$ & $\begin{array}{c}\text { Sem. tubule } \\
(\mu)\end{array}$ & $\begin{array}{l}\text { Sem. vesicle } \\
(\mathrm{mg} / \mathrm{g})\end{array}$ & $\underset{(m g / g)}{\text { Epididymis }}$ \\
\hline $\begin{array}{l}\text { Time } \\
\text { Social } \\
T \times S \\
\text { Error }\end{array}$ & $\begin{array}{r}3 \\
2 \\
6 \\
96\end{array}$ & $\begin{array}{r}145 \cdot 397 \\
2 \cdot 261 \\
9.986 \\
3.544\end{array}$ & $\begin{array}{l}1 \cdot 794^{*} \\
2 \cdot 255^{*} \\
0 \cdot 186^{* *} \\
0.122\end{array}$ & $\begin{array}{l}920 \cdot 308^{*} \\
591 \cdot 768^{* *} \\
165 \cdot 476^{* *} \\
100 \cdot 720\end{array}$ & $\begin{array}{c}55 \cdot 280^{*} \\
15 \cdot 875^{* *} \\
4 \cdot 052^{*} \\
1 \cdot 010\end{array}$ & $\begin{array}{l}0.586^{*} \\
0.012 \\
0.032 * \\
0.010\end{array}$ \\
\hline L.S.D. $\dagger$ & & 1.77 & 0.33 & $9 \cdot 46$ & 0.09 & 0.94 \\
\hline
\end{tabular}

* Significant at $P<0.05$ level on the basis of the pooled comparison.

** Significant at $P<0.05$ level on the basis of single degree of freedom comparisons.

$\dagger$ The least significant differences are given for making comparisons of means in Text-fig. 1 and Text-fig. 2.

At 36 days, the seminal vesicles weighed approximately the same in all groups (Text-fig. 1, lower left). By 48 days, the males exposed to an adult male had smaller seminal vesicles than those in either of the other social environments and, thereafter, the seminal vesicles continued to remain smaller than those of males exposed to an adult female.

The epididymal weights represent the only measure of reproductive status in which the males exposed to an adult male exceeded either of the other treatment groups (Text-fig. 1, lower right). Although the male group exceeded the no-

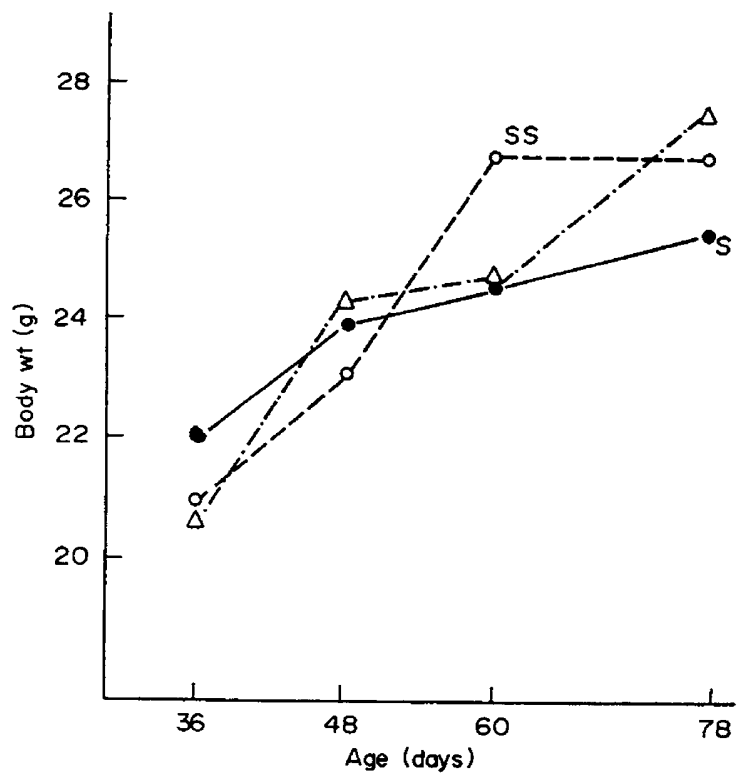

Text-rig. 2. The mean body weights of mice killed at $36,48,60$ and 78 days of age following rearing under three social conditions $(O$, female present; $\bullet$, male present; $\Delta$, no adult). 
adult group at 36 days, they fell to a mean weight below both treatment groups at 78 days.

The mean body weight of each of the treatment groups at each age is shown in Text-fig. 2. At 36 and 48 days of age, there were no significant differences between the body weights of the males in the treatment groups. At 60 days of age, males exposed to an adult female weighed more than did males reared in either of the other social environments and at 78 days of age, males reared apart from adults weighed more than males reared with an adult male.

\section{DISCUSSION}

This study differs from previous attempts to determine the rôle of the social environment on male sexual development by contrasting the effects of the presence of an adult female with that of an adult male. Previously, only the stimulus qualities of the adult female were investigated (Drori \& Folman, 1964; Folman \& Drori, 1966; Fox, 1968). The difference in experimental design proved to be important because it revealed that the presence of an adult male had an inhibitory effect on male sexual development, especially late in reproductive maturation.

The differences in testicular weight between the males reared under three social environments showed that the presence of an adult female stimulated testicular development, especially in comparison with mice exposed to an adult male. The stimulatory effect attributable to the female disappeared by 78 days because, at that age, the testes were essentially the same weight in the group exposed to an adult female and the groups denied the presence of an adult. The inhibitory effect of the adult male on the testicular weight was most prominent at 78 days of age.

Only a slight enlargement of the seminiferous tubules occurred over the 8-week period embraced by this study, whereas the testicular size increased markedly. Furthermore, the differences between the treatment groups did not coincide well with the changes in testicular weight. A similarly inconsistent relationship can be seen in the data presented by Fox (1968). In his study, the testes of males exposed to a female were heavier at 36 days than at 56 days of age but the seminiferous tubules increased in diameter over this period. Such discrepancies and the possibility of distortion during fixation and sectioning make these data less useful than the other measures of reproductive maturity.

Changes in the weight of the epididymis and seminal vesicles are androgendependent and thus secondarily reflect changes in luteinizing hormone output. The differences observed in these measures at 36 days of age showed that while the presence of an adult male had no effect on seminal-vesicle weight, it did result in a higher mean epididymal weight, thus indicating an increased androgen output. This apparent increase in androgen secretion was surprising because the testes of these males were relatively smaller than those from males in other social environments. Stimulation of androgen production by the presence of an adult male was apparently short-lived because, at later ages, there were either no differences in epididymal and seminal-vesicle weights between the treatments, or the groups exposed to a male displayed evidence of 
decreased androgen output. Inhibition of androgen activity by the presence of an adult male was most marked at 78 days of age as indicated by the lower weights of both of the accessory glands of males in this group.

The inhibitory effect of the presence of an adult male on the reproductive organs of young male cage-mates contrasts sharply with the stimulatory action of an adult male on immature females (Vandenbergh, 1967). Acceleration of the development of females and inhibition of that of males confer a considerable reproductive advantage upon an adult male in a population. It provides the male with a ready supply of nubile females and may reduce the competition for these females. As yet, no behavioural tests have been conducted to determine whether there are differences in the sexual competence of the males reared in different environments. Furthermore, the contrasting rôle of the male may be operative only at relatively low population densities in rodents because as Christian \& Davis (1964) and Terman (1968) have shown, high population densities result in reproductive suppression in both sexes.

Although the stimulative effect of the male on female sexual development operates through a pheromonal mechanism (Vandenbergh, 1969), odours may not be responsible for the reproductive inhibition of young males. Terman (1968), using Peromyscus maniculatus bairdii, showed that exposing pairs of mice to the odour of bedding material drawn from a dense population resulted in stimulation rather than inhibition of the reproductive tracts in both sexes. Although other sensory modalities such as vision and audition have not been excluded, it is most likely that the inhibition found in this study occurred as a result of the direct physical presence of an adult male. Support for this point also comes from the finding by Folman \& Drori (1966) that mating activities rather than female odours were responsible for maintenance of the reproductive tract in adult male rats.

Even though the reproductive inhibition of young males can be attributed to the presence of a male, this does not necessarily indicate that the inhibition is a consequence of fighting. In the current study, there was no evidence of physical violence between the males; none of the mice was scarred and fights were never observed during cursory observations of the groups. The absence of fighting contrasts markedly with the results reported by Fox (1968). A high degree of social conflict occurred in his groups reared to 56 days of age with an adult female. This difference could be due to differences in the strains of mice used or in the cage size. The cages used in the current study had almost double the floor space of the cages used by Fox.

\section{AGKNOWLEDGMENTS}

I thank Mrs Elizabeth Frye and Mrs Janet Goldenbaum for technical assistance. This study was supported in part by United States Public Health Service Research Grant MH-16870.

\section{REFERENCES}

Ghristian, J. J. \& Davis, D. E. (1964) Endocrines, behavior and population. Science, N.Y. 146, 1550. Drori, D. \& Folman, Y. (1964) Effects of cohabitation on the reproductive system, kidneys and body composition of male rats. F. Reprod. Fert. 8, 351. 
Folman, Y. \& DroRi, D. (1966) Effects of social isolation and of female odours on the reproductive system, kidneys and adrenals of unmated male rats. J. Reprod. Fert. 11, 43.

Fox, K. A. (1968) Effects of prepubertal habitation conditions on the reproductive physiology of the male house mouse. F. Reprod. Fert. 17, 75.

MARSDEN, H. M. \& BRONSON, F. H. (1964) Estrous synchrony in mice: alteration by exposure to male urine. Science, N.Y. 144, 1469.

Parkes, A. S. \& Bruce, H. M. (1961) Olfactory stimuli in mammalian reproduction. Science N.Y. 134, 1049.

Stees, R. G. D. \& Torrie, J. H. (1960) Principles and procedures of statistics. McGraw-Hill, New York.

STEINACH, E. (1936) Zur Geschichte des männlichen Sexualhormons und seiner Wirkung am Säugetier und beim Menschen. Wien. Klin. Wschr. 49, 161.

TERMAN, C. R. (1968) Inhibition of reproductive maturation and function in laboratory populations of prairie deermice: A test of pheromone influence. Ecology, 49, 1169.

VANDENBERGH, J. G. (1967) Effect of the presence of a male on the sexual maturation of female mice. Endocrinology, 81, 345.

VANDENBERGH, J. G. (1969) Male odor accelerates female sexual maturation in mice. Endocrinology, 84, 658.

Whrrren, W. K. (1966) Pheromones and mammalian reproduction. In: Advances in Reproductive Physiology, Vol. 1, p. 155. Ed. A. McLaren. Academic Press, London.

Whrten, W. K., Bronson, F. H. \& Greenstein, J. A. (1968) Estrus-inducing pheromone of male mice: transport by movement of air. Science, N.Y. 161, 584 . 